\title{
Metallo-Terpyridine-Modified Cellulose Nanofiber Membranes for Papermaking Wastewater Purification
}

\author{
Mohammad Hassan ${ }^{1,2} \cdot$ Enas Hassan ${ }^{1} \cdot$ Shaimaa M. Fadel $^{1} \cdot$ Ragab E. Abou-Zeid $^{1}$ \\ Linn Berglund ${ }^{3} \cdot$ Kristiina Oksman $^{3,4}$
}

Received: 1 August 2017 / Accepted: 11 September 2017 / Published online: 14 November 2017

(c) The Author(s) 2017. This article is an open access publication

\begin{abstract}
Metallo-terpyridine compounds and polymers exhibit unique optical, electrical, magnetic and antimicrobial properties. Recently, metallo-terpyridine-modified cellulosic films with interesting porous structure, that exhibit these properties, have been prepared. Herein we report the use of $\mathrm{Cu}$-terpyridine-modified oxidized cellulose nanofibers (OXCNF-Cu-Tpy) as membranes for treatment of effluents of paper mills to produce re-usable water. The OXCNF-CuTpy was prepared by modification of TEMPO-oxidized CNF (OXCNF) using copper(II) complex of $4^{\prime}$-Chloro [2,2':6',2'] terpyridine. The modification was proven by elemental analysis and Fourier transform infrared spectroscopy. The
\end{abstract}

Kristiina Oksman

kristiina.oksman@1tu.se

Mohammad Hassan

ml.hassan@nrc.sci.eg

Enas Hassan

ea.hassan@nrc.sci.eg

Shaimaa M. Fadel

sm.fadel@nrc.sci.eg

Ragab E. Abou-Zeid

re.abouzeid@nrc.sci.eg

Linn Berglund

linn.berglund@1tu.se

1 Cellulose and Paper Department and Centre of Excellence for Advanced Sciences, National Research Centre, 33 El-Behouth street, Dokki, Giza 12622, Egypt

2 Egypt Nanotechnology Centre, Cairo University, El-Sheikh Zaid, 6th October City 12588, Egypt

3 Department of Engineering Sciences and Mathematics, Luleå University of Technology, Luleå, Sweden

4 Fibre and Particle Engineering, Faculty of Technology, University of Oulu, FIN-90014, Oulu, Finland prepared OXCNF-Cu-Tpy was also characterized using $\mathrm{X}$-ray diffraction and transmission electron microscopy. The prepared membranes were evaluated regarding their microscopic structure using scanning electron microscopy, atomic force microscopy, contact angle measurement, water flux and rejection of sub-micron size suspended particles in papermaking wastewater effluent. Chemical modification of OXCNF with the $\mathrm{Cu}$-Tpy groups significantly increased pure water flux of the membranes by about 52 and $194 \%$ depending on pressure used during filtration (0.5 and $1 \mathrm{MPa}$, respectively). Although both $\mathrm{OXCNF}$ and $\mathrm{OXCNF}-\mathrm{Cu}-\mathrm{Tpy}$ exhibited high efficiency in removing the sub-micron size suspended particles from wastewater effluent, $\mathrm{OXCNF}-\mathrm{Cu}-$ Tpy membranes showed about $30 \%$ higher flux rate than OXCNF membranes.

Keywords Rice straw · Cellulose nanofibers ·

Terpyridine $\cdot$ Papermaking $\cdot$ Wastewater $\cdot$ Membranes

\section{Introduction}

Terpyridine metal complexes, polymers bearing terpyridine moieties, and polymers based on terpyridine units have been extensively studied due to their interesting optical, electrical, magnetic, antimicrobial properties. Different polymeric architectures (dendrimers, hyperbranched, and linear) containing or based on terpyridine have been published [1-3]. Whereas there are a large number of publications concerned with polymers bearing different terpyridine ligands, the preparation of the first, terpyridine-modified, cellulose polymer was reported during 2012 in Professor Newkome' laboratories at the University of Akron through his collaboration with our group at the National Research Centre in Egypt. During that work, surfaces of cellulose nanocrystals were 
modified via an etherification reaction, i.e., true chemical bonding, between the hydroxyl groups at the surface of cellulose nanocrystals with chloro-terpyridine ligands followed by attachment of different terpyridine metal complexes with divalent metal ions. These modified nanocrystals showed interesting optical and electrical properties [4-6].

The preparation of the metallo-terpyridine modified cellulosic material followed a supramolecular route, whereby carboxmethyl cellulose and TEMPO-oxidized cellulose nanofibers were reacted with mono-terpyridine complex of different metals ions [7, 8]; the supramolecular complexes were formed as a result of reaction between the carboxylic groups of the cellulosic derivatives and the metal complex of terpyridine through coordination bonds. The modification via supramolecular route was much easier than the etherification route regarding simplicity of purification and reaction conditions. Films casted from terpyridine-modified cellulose nanofibers (CNF) exhibited nanoporous structure with interesting optical properties, mechanical, and antibacterial properties [8]. More recently, terpyridine functionalized CNF were used as smart battery separators [9].

Impetus for this work includes the increasing demand for clean and fresh water due to the world's growing population. An important source for water exists as wastewater resulting from heavy consumption by industry. Papermaking is one of the largest water consuming processes that involve the use of huge amount of water at the different stages of paper production. Most of water used in papermaking during sheet formation is recycled but finally huge amounts of water containing highly suspended particles of sub-micron size remain and should be treated to remove these particles to allow re-use of the wastewater. Ultrafiltration and nanofiltration are among the technologies that can be used to do this step [10,11]. Development of a cheap filter that can effectively remove these particles at reasonable flux is a challenge.

Use of CNF in membranes has recently attracted the attention of researchers due to the unique properties of these CNF regarding availability of cellulose and ability to form very thin membranes with nanoporous structure. CNF membranes could be prepared from the aqueous nanofibers suspensions using simple techniques such as coating or vacuum filtration. However, one of the shortcomings of these membranes is their relatively low water flux for industrial applications, especially for effluents with a high concentration of suspended pollutants. Few publications have studied on how to increase the flux rate of membranes made from cellulose nanofibers. Some authors studied the addition of nanoparticles during membrane formation such as with silica particles [12]. Others examined water exchange of wet CNF film by a less polar solvent before drying [13, 14].

Previous studies using membranes made from CNF investigated their use for filtration of different high molecular weight materials and small size nanoparticles
[15]. However, using CNF membranes for purification of wastewater produced from paper industry was rarely studied. To the best of our knowledge, the only published work is that of Varanasi et al. [12] who studied the use of calcium chloride and trisodium trimetaphosphate cross-linked 2,3-dicarboxylic acid CNF thin films $(\sim 0.85 \mu \mathrm{m}$ thickness) for filtration of process water from a disc filter papermaking process. The performance of the prepared $\mathrm{CaCl}_{2}$ crosslinked membrane was similar to commercial polyethersulfone membrane regarding flux and fouling tendency. Wastewater flux of about $60-70 \mathrm{l} / \mathrm{h} /$ $\mathrm{m}^{2}$ was recorded after filtration for $2 \mathrm{~h}$ at 3 bar pressure, while pure water flux ranged from 125 to $2251 \mathrm{~h} / \mathrm{m}^{2}$ was recorded at the same pressure and time.

Our previous investigation showed that highly porous films of about $0.08 \mathrm{~mm}$ thickness with surface pore size of less than $100 \mathrm{~nm}$ and antimicrobial properties could be prepared by simple casting of metallo-terpyridinemodified TEMPO-oxidized CNF [8]. The aim of the current work focused on improving water flux of ultra-thin film membranes prepared by chemical modification of TEMPO-oxidized CNF with $\mathrm{Cu}$-Tpy ligands and to use the prepared membrane for water purification of paper mill effluent.

\section{Materials and Methods}

\subsection{Materials}

Rice straw was collected from local fields in Giza, Egypt. Sodium hydroxide, $4^{\prime}$-Chloro $\left[2,2^{\prime}: 6^{\prime}, 2^{\prime \prime}\right]$ terpyridine (Cltpy; assay $99 \%$ ), copper sulfate, sodium hypochlorite solution (12 wt\%), 2,2,6,6-tetramethyl-1-piperidinyloxy (TEMPO), $\mathrm{NaOH}$, sodium chlorite, acetic acid, ethanol, and isopropyl alcohol were reagent grade chemicals and used as received. (Sigma-Aldrich, St. Louis, MO, USA). Polyamide-amineepichlorohydrin (PAE) was commercial grade (solid content $\sim 33 \mathrm{wt} \%$, Solines, Wilmington, DE, USA). PAE solution was diluted to $1 \mathrm{wt} \%$ with distilled water prior to use.

\subsection{Preparation of Rice Straw Pulp}

Bleached pulp was prepared from the rice straw as described before [8]. Pulping of rice straw was first obtained by alkali treatment using $15 \% \mathrm{NaOH}(\mathrm{w} / \mathrm{w}$, based on oven-dried of straw) at $150{ }^{\circ} \mathrm{C}$ for $2 \mathrm{~h}$. The produced pulp was bleached using sodium chlorite/acetic acid mixture at $80{ }^{\circ} \mathrm{C}$ for $1 \mathrm{~h}$ [16]. Chemical composition of the bleached pulp was determined according to the previously published methods [17] 
and was: Klason lignin $1.46 \%$, $\alpha$-cellulose $69.7 \%$, hemicelluloses $19.7 \%$, and acid-insoluble ash content $8.9 \%$.

\subsection{Isolation of TEMPO-Oxidized CNF}

TEMPO-oxidized CNF was isolated from bleached pulp as described in the literature [14]. Bleached pulp (3 g) was dispersed in distilled water $(400 \mathrm{ml})$ with TEMPO $(0.048 \mathrm{~g}$, $0.3 \mathrm{mmol})$ and sodium bromide $(0.48 \mathrm{~g}, 4.8 \mathrm{mmol})$. Then $30 \mathrm{ml}$ of sodium hypochlorite solution was then added with stirring and the $\mathrm{pH}$ was adjusted to 10 . At the end of reaction the $\mathrm{pH}$ was adjusted to 7 and the product was centrifuged at $10,000 \mathrm{rpm}$. The product was further purified by repeated washing with water, dispersion, and centrifugation. Finally, the product was purified by dialysis for 1 week against deionized water with 3500 MWCO Spectra/Por dialysis tubing. TEMPO-oxidized fibers were homogenized using a two-chamber high-pressure homogenizer (APV-2000, SPX, Silkeborg, Denmark) after being diluted with water to $1 \%$ consistency and passed twice through the device. The pressure was kept at 40 bar in one chamber and 400 bar in the other chamber. Carboxylic content of the oxidized nanofibers was $0.42 \mathrm{mmol} / \mathrm{g}$ according to TAPPI Test Method $\mathrm{T} 237 \mathrm{~cm}-98$.

\subsection{Surface Modification and Characterization of OXCNF}

Modification of OXCNF with $\mathrm{Cu}-\mathrm{Tpy}$ ligand was carried out as detailed in the literature [8]. The $4^{\prime}-\mathrm{Cl}$-terpyridine- $\mathrm{Cu}^{\mathrm{II}}$ adduct ( $\mathrm{Cu}$-Tpy) was first synthesized according to the previously published procedure by reacting $4^{\prime}-$ Chloro $\left[2,2^{\prime}: 6^{\prime}\right.$, $\left.2^{\prime \prime}\right]$ terpyridine with copper(II) chloride [17]. Reaction of $\mathrm{Cu}$-Tpy with OXCNF was carried out by reacting 0.25 gram of OXCNF with 0.1 -mmole of $\mathrm{Cu}$-Tpy at $\mathrm{pH} 10,70{ }^{\circ} \mathrm{C}$ for $3 \mathrm{~h}$ to generate the terpyridine-modified oxidized CNF (OXCNF-Cu-Tpy). The product was separated by centrifugation at 10,000 rpm and purified by washing with ethanol/ water solution and finally dialyzed against water till constant $\mathrm{pH}(\mathrm{pH} \sim 7)$ and conductivity of water $(\sim 5 \mu \mathrm{S} / \mathrm{cm})$.

The prepared OXCNF-Cu-Tpy was characterized using Fourier Transform infrared spectroscopy using a JASCO FTIR 800 E spectrometer; the samples were measured using the $\mathrm{KBr}$ disc technique. Elemental analysis was conducted on a Vario EI Elementar instrument. X-ray diffraction patterns were recorded using Empyrean X-ray diffractometer (PANalytical, Netherlands). Crystallinity index was calculated from the X-ray diffraction patterns according to the following equation [18]:

$\mathrm{CrI}=\left(\mathrm{I}_{002}-\mathrm{I}_{\mathrm{am}}\right) / \mathrm{I}_{002}$, where $\mathrm{I}_{002}$ is the intensity of the diffraction profile at the position of 002 peak $\left(2 q=22.7^{\circ}\right)$ and $I_{a m}$ is the intensity at about $2 q=18^{\circ}$.
Transmission electron microscopy was carried out using high-resolution transmission electron microscopy (JEM2100 transmission electron microscope, JEOL, Tokyo, Japan). Microscopic features were investigated using a FEI Quanta 200 scanning electron microscope (FEI Company, Eindhoven, The Netherlands) at an acceleration voltage of $20 \mathrm{kV}$.

\subsection{Wastewater}

Wastewater effluent was kindly supplied by Rakta Company for Paper, Alexandria, Egypt, from the drainage of a papermaking machine from recycled fibers. The wastewater was left to settle the large particles and the water containing suspended particles was separated. Particle size distribution of suspended particles was characterized using zetasizer instrument (Malvern Instruments, Malvern Worcestershire, UK). Conductivity and total dissolved solids were measured using electric conductivity meter (Jenway 4510, Jenway, Staffordshire, UK). The solid content of the wastewater fraction used was determined to be $0.3 \mathrm{~g} / \mathrm{l}$, the $\mathrm{pH}$ of wastewater was 6.9 , conductivity was $836 \mu \mathrm{S} / \mathrm{cm}$, and total dissolved solids was $505 \mathrm{mg} / \mathrm{l}$.

\subsection{Nanofiber Membranes}

OXCNF or OXCNF-Cu-Tpy (0.006 g oven-dry weight) in water suspension with concentration of $0.1 \mathrm{wt} \%$ was filtered on $5-\mathrm{cm}$ hardened filter paper using vacuum pump. In case of OXCNF, 4\% PAE crosslinker (based on oven-dry weight of $\mathrm{CNF}$ ) was added to the mixture before membranes making. The water of the obtained wet membranes was first exchanged by isopropyl alcohol then the membranes were dried at $105^{\circ} \mathrm{C}$ for $30 \mathrm{~min}$.

\subsection{Evaluation of Membrane Properties}

\subsubsection{Atomic Force Microscopy (AFM)}

AFM was used to study the nanoscale surface characteristics of the membranes using a Veeco Multimode Scanning Probe (Veeco instruments, Plainview, NY, USA) in tapping mode and a tip model TESPA (antimony (n) doped Si), (Bruker, USA). Height and amplitude images were recorded and the root-mean square roughness (RMS) values were also measured with the Nanoscope V software from the collected AFM height images. The reported values are the average based on three different measurements each on a surface area of $225 \mu \mathrm{m}^{2}$. All measurements were conducted in air at room temperature. 


\subsubsection{Contact Angle Measurements}

The water contact angle of the membranes was measured using an EASYDROP measuring system and calculated with drop shape analysis DSA1 control software, Krüss (Germany), using a sessile drop technique. A water drop of $4 \mu$ was placed onto the membranes at four separate places for calculation of the average contact angles.

\subsubsection{Pure Water Flux}

The water flux of the membranes was measured using a dead end Stirred cell, (Sterlitech HP4750, USA). Prior to the measurements, discs with a diameter of about $5 \mathrm{~cm}$ were cut out from the membranes and soaked in water for one hour to ensure equilibration of the membrane. The conditioned membranes were placed in the dead end cell on a stainless steel porous support disk and water was passed through the membranes at room temperature at a differential pressure of $1 \mathrm{MPa}$; maintained using $\mathrm{N}_{2}$ gas. The quantity of water that passed through the membrane for a defined time interval was weighed accurately and the flux was calculated $\left(1 / \mathrm{h} / \mathrm{m}^{2}\right)$ for the active filtration area $\left(14.6 \mathrm{~cm}^{2}\right)$.

\subsubsection{Rejection Efficiency}

Removal of wastewater particles by the prepared membranes was evaluated by measuring optical density at $600 \mathrm{~nm}\left(\mathrm{OD}_{600}\right)$ of the wastewater before and after filtration through the membranes. The suspension was filtered in the dead end cell as in case of measuring water flux mentioned above. The filtrate was collected and the turbidity was examined using UV-Visible spectrometer (Shimadzu, Japan) and expressed as OD.
The capability of the prepared membranes to remove wastewater particles from water was calculated using the following formula:

$$
\begin{aligned}
\text { Rejection }(\%)= & {\left[\left(\text { Control OD } 600-\text { Sample } \mathrm{OD}_{600}\right) /\right.} \\
& \text { Control OD } 600] \times 100
\end{aligned}
$$

\section{Results and Discussion}

\subsection{OXCNF and OXCNF-Cu-Tpy}

Surface modification of OXCNF with Cu-Tpy using an equimolar ratio of $\mathrm{Cu}$-tpy to carboxylic group content of OXCNF is expected to produce a penta co-ordinate complex as shown in scheme 1 [8, 19]. Due to water solubility of $\mathrm{Cu}$-Tpy salt, the produced OXCNF-Cu-Tpy possessed hydrophilic character similar to that of OXCNF and a gellike product in water was obtained.

OXCNF isolated from rice straw pulp shows very thin width (3-5 $\mathrm{nm}$ ) and several microns in length (Fig. 1). TEM images in Fig. 1 also showed that modification of OXCNF with $\mathrm{Cu}$-tpy complex did not noticeably affect the morphology and dimensions of the OXCNF, suggesting surface modification of the nanofibers occurred without affecting the internal cellulose chains [8].

Elemental analysis of OXCNF-Cu-Tpy gave a nitrogen content of $0.47 \%$, which corresponds to $0.11 \mathrm{mmole} / \mathrm{g}$ of $\mathrm{Cu}-$ Tpy. The lower content of Cu-Tpy of the OXCNF-Cu-Tpy than the total carboxylic content of OXCNF $(\sim 0.42 \mathrm{mmole} / \mathrm{g})$ was ascribed to that the total carboxylic content of OXCNF includes both of the carboxylic groups at the surface and inside the nanofibrils while the reaction occurs mainly at the<smiles>CC(C)C(C(=O)O[Na])C(C)C(=O)O[Na]</smiles>

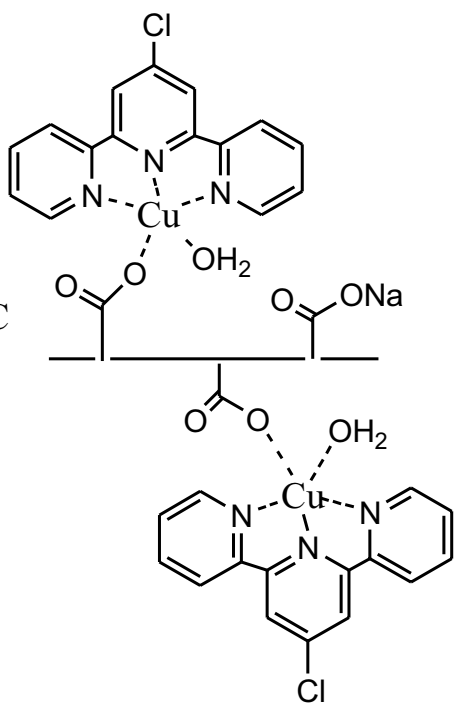

Scheme 1 Reaction between OXCNF and terpyridine copper complex (solid line depicts cellulose chain) 
Fig. 1 TEM of a TEMPO-oxidized CNF and $\mathbf{b}$ Terpyridinemodified TEMPO-oxidized CNF. Inside pictures are to show change in color due to modification
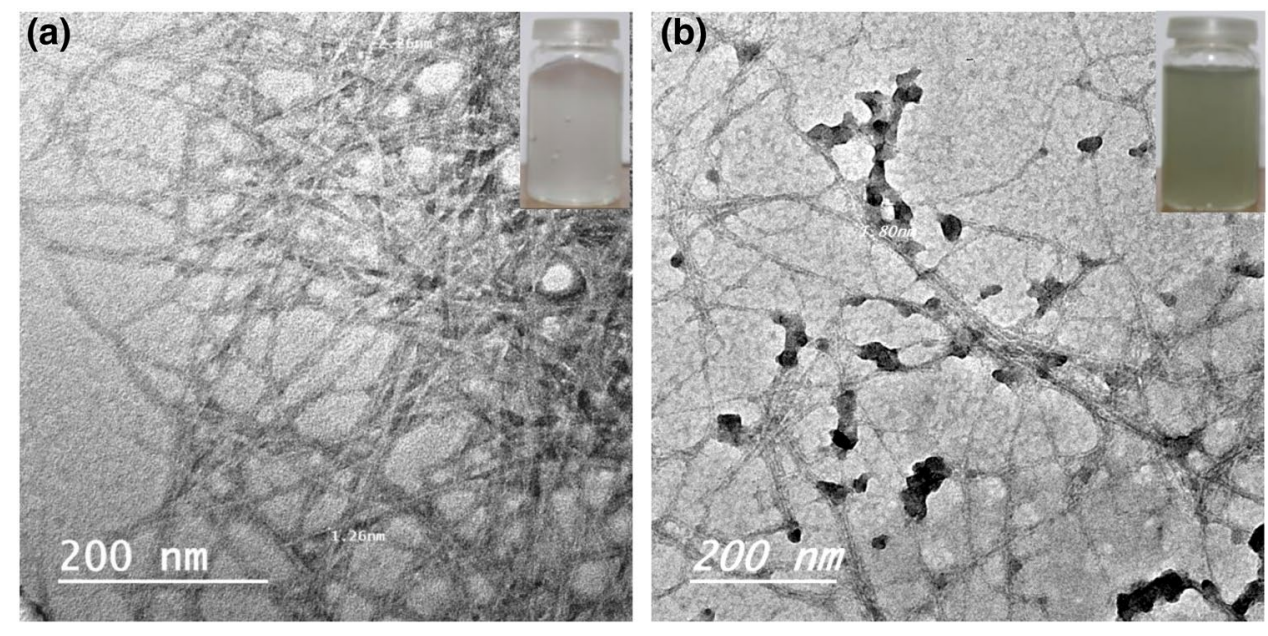

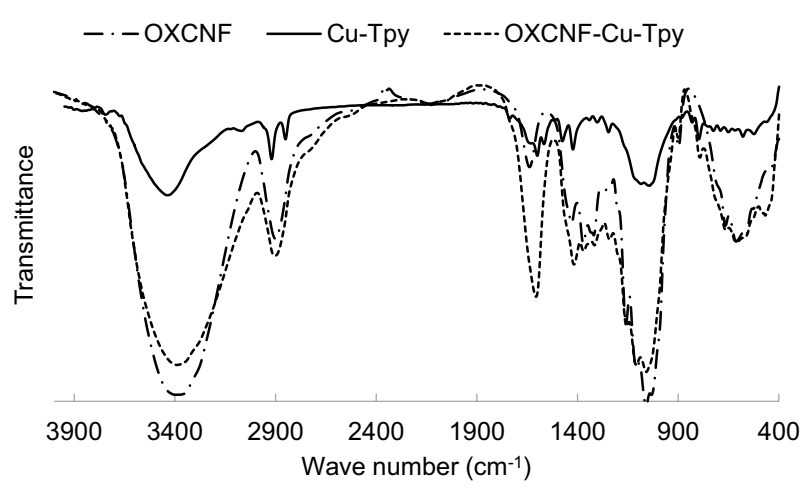

Fig. 2 FTIR spectra of OXCNF, Cu-Tpy, and OXCNF-Cu-Tpy

surface of CNF due to less steric hindrance. The obtained OXCNF-Cu-Tpy has greenish blue color and kept its high water affinity due to the polar nature of the complex formed.

FTIR spectra of OXCNF, OXCNF-Cu-Tpy, and Cu-Tpy are shown in Fig. 2. OXCNF showed the known bands of cellulose skeleton in addition to the appearance of carboxylate groups' band at $1640 \mathrm{~cm}^{-1}$. As shown in the figure, the main change in the spectrum of OXCNF due to modification by the $\mathrm{Cu}$-Tpy groups was the shift in the band of the carboxylate group from 1640 to $1600 \mathrm{~cm}^{-1}$ and significant increase in its intensity. Otherwise, since positions of most bands of $\mathrm{Cu}$-Tpy, mainly the bands of hydroxyl groups at $3440 \mathrm{~cm}^{-1}, \mathrm{C}-\mathrm{H}$ groups at 2850 and $2920 \mathrm{~cm}^{-1}$, and those of the aromatic skeleton at 1605 , 1575 , and $1480 \mathrm{~cm}^{-1}$ [20] were within the regions of cellulose bands, no significant differences between the spectra of OXCNF and OXCNF-Cu-Tpy were noticed.

$\mathrm{X}$-ray diffraction patterns (Fig. 3) of OXNCF and OXCNF-Cu-Tpy also did not also exhibit significant differences when compared with the peaks of cellulose I structure at $2 \mathrm{q} 22.7,16.5$, and 15.2, which belong to diffraction

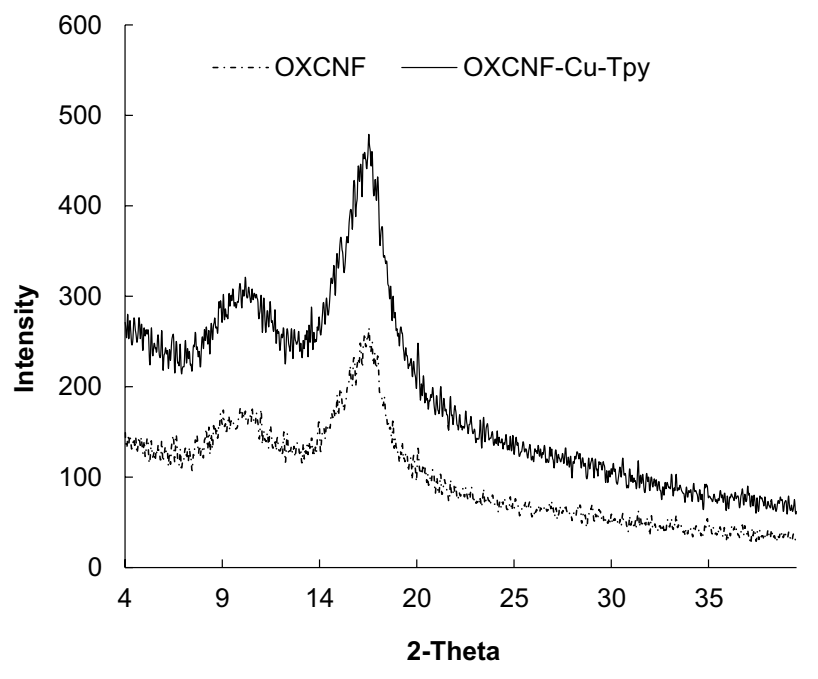

Fig. 3 XRD of OXCNF and OXCNF-Cu-Tpy

from (200), (110), and (1-10) planes, respectively [8]. The crystallinity index for OXCNF and OXCNF-Cu-Tpy was 69.5 and 69, respectively. These results confirmed occurrence of the modification only at the surface of OXCNF without changes in their supramolecular structure.

\subsection{OXCNF and OXCNF-Cu-Tpy Membranes}

Our previous investigation reported the formation of highly porous films from OXCNF and OXCNF-Cu-Tpy [8]. As shown in Fig. 4, the surface of both films was characterized by a highly porous structure with wide pore size variation but limited to diameter less than $100 \mathrm{~nm}$. Air permeability experiments revealed a higher porosity for the OXCNF-CuTpy film than the OXCNF; the time required for passing $100 \mathrm{ml}$ of air through an area of one inch $^{2}$ of the films was 447 and 668 s, respectively [8]. 

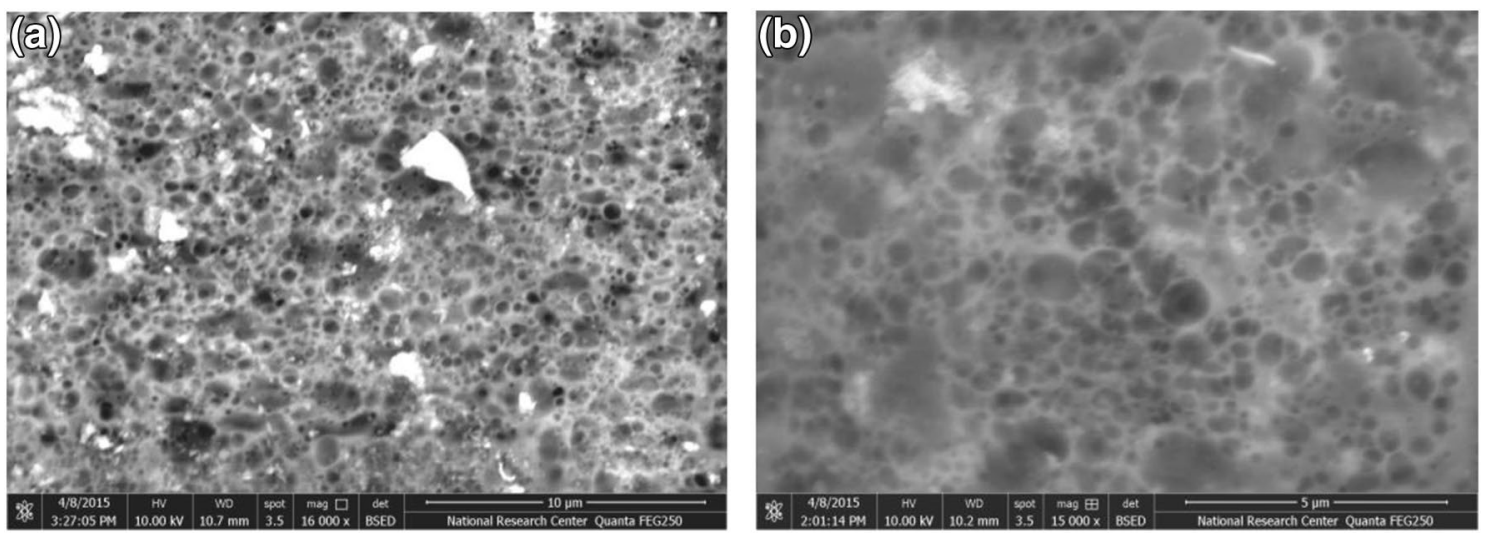

Fig. 4 SEM images of a OXCNF and b OXCNF-Cu-Tpy films
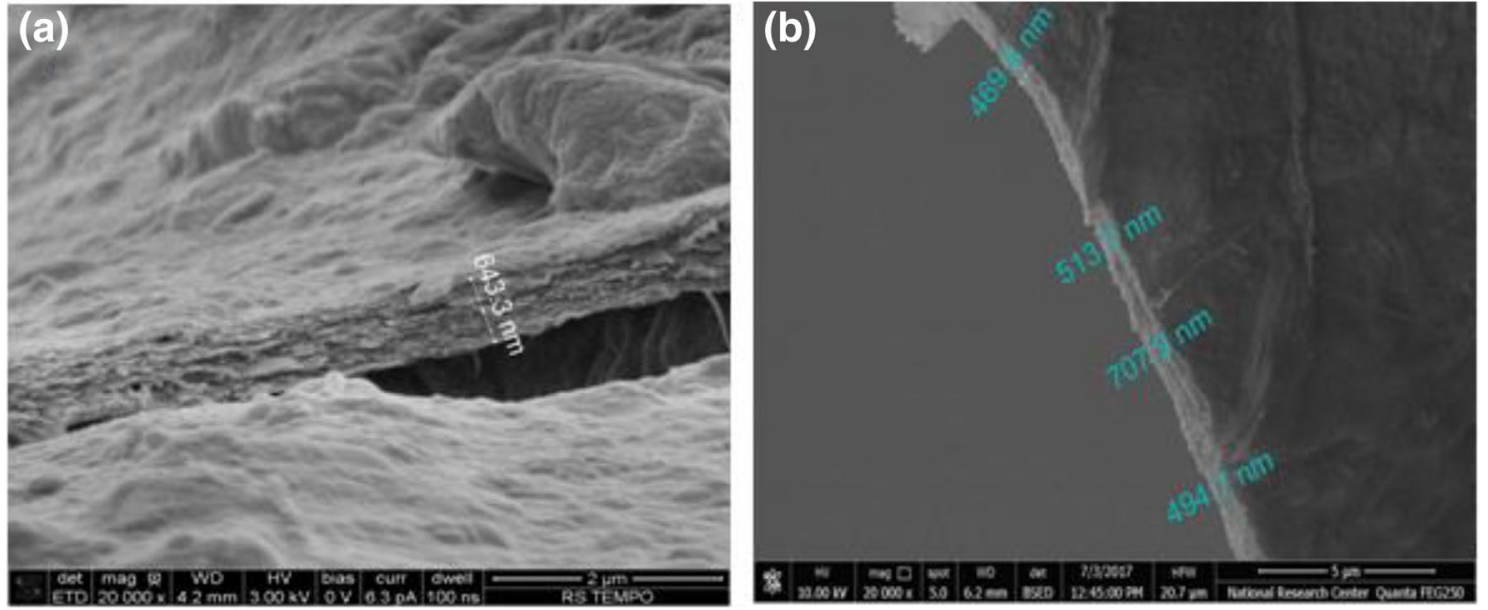

Fig. 5 SEM image of cross-section of a OXCNF, and $\mathbf{b}$ OXCNF-Cu-Tpy film formed on hardened filter paper

Ultra-thin membranes from OXCNF and OXCNF-CuTpy were formed on hardened filter paper. Thickness of the formed membranes ranged from about $0.55-0.64 \mu \mathrm{m}$ for OXCNF and OXCNF-Cu-Tpy membranes, respectively (Fig. 5).

The surface characteristics of OXCNF and OXCNF-CuTpy membranes were investigated on nanoscale using AFM. The roughness measured from the height images was 177.7 $( \pm 6.5)$ and $231.3( \pm 42.1) \mathrm{nm}$ for OXCNF and OXCNF-CuTpy membranes, respectively. The increase in roughness could be attributed to the introduction of the terpyridine moieties at the surface of the OXCNF. This was also clear from the amplitude images where an overall rougher surface was apparent in case of OXCNF-Cu-Tpy membrane (Fig. 6). Upon forming the membranes by vacuum filtration, the OXCNF will be arranged forming a more uniform film than in case of the OXCNF-Cu-Tpy where the bulky terpyridine groups at the surface of the nanofibers resulted in formation of more uneven film and a higher roughness accordingly.
The membranes of OXCNF and OXCNF-Cu-Tpy formed on the filter paper were also characterized by water contact angle measurement to get an idea about the wettability of the membranes and water penetration through them. The measurements show that OXCNF-Cu-Tpy membrane had higher contact angle than that of OXCNF due to the introduction of the terpyridine groups at the surface of the nanofibers. The average contact angle after $1 \mathrm{~min}$ of exposure to water was $42^{\circ}( \pm 4.1)$ and $59^{\circ}( \pm 3.2)$ for OXCNF and OXCNF$\mathrm{Cu}$-Tpy membranes, respectively (Fig. 7). However, it was noted that, in case of OXCNF, the water drop was spread over the surface of the membrane causing a decrease in the contact angle, while in case of OXCNF-Cu-Tpy, the water drop did not spread on the surface but it rather penetrated the membrane and was collected under the lower surface of the membrane. This caused the noticed increase in water contact angle shown in Fig. 7 at the beginning of the measurement. 
Fig. 6 AFM images in the amplitude mode of OXCNF and OXCNF-Cu-Tpy membranes
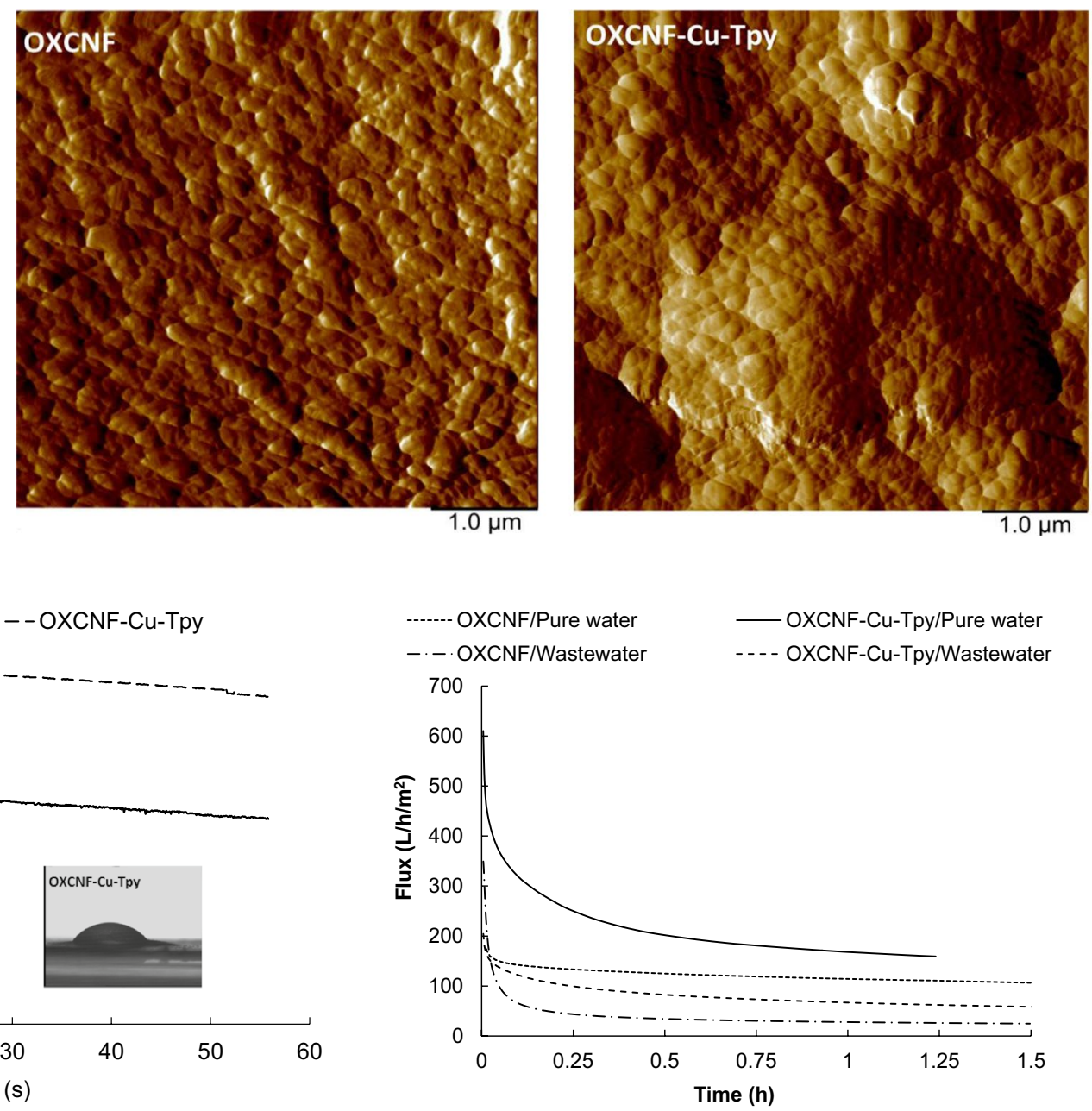

(a)

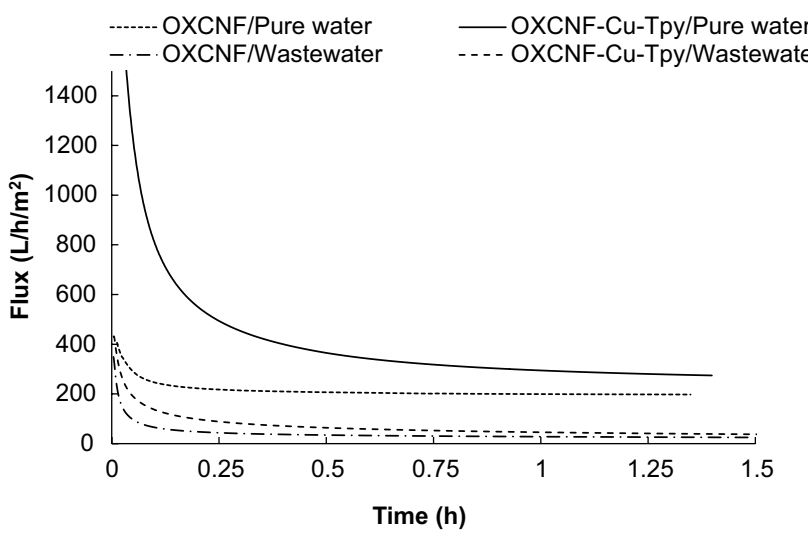

(b)

Fig. 8 Water flux curves of OXCNF and OXCNF-Cu-Tpy membranes for filtration of pure water and paper mill wastewater at a $0.5 \mathrm{MPa}$ and $\mathbf{b} 1 \mathrm{MPa}$

the structure of the membrane more porous than in case of the non-modified OXCNF.

The OXCNF and OXCNF-Cu-Tpy membranes were tested for purification of paper mill wastewater from the ence of $\mathrm{Cu}$-Tpy groups at the surface of nanofibers will keep 


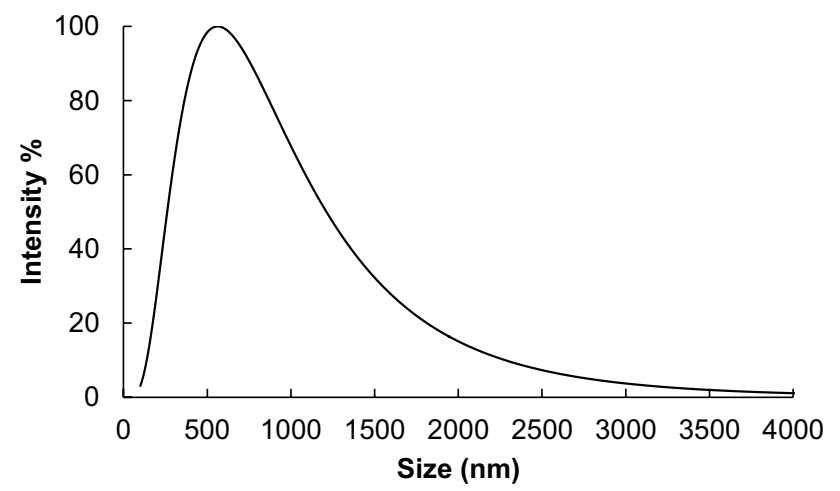

Fig. 9 Particle size distribution of wastewater fraction used in the test

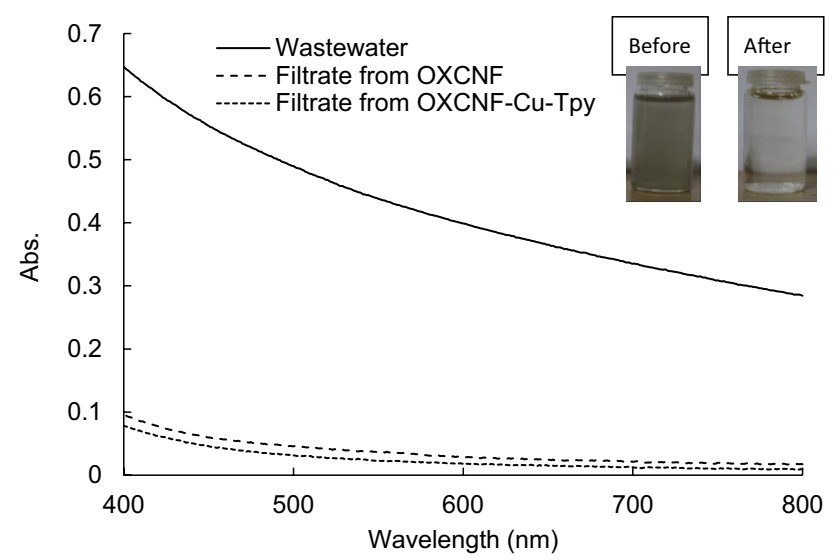

Fig. 10 Visible absorbance spectra of wastewater before and after filtation using OXCNF and OXCNF-Cu-Tpy membranes at $1 \mathrm{MPa}$ pressure. inset images depict the wastewater before and after filtration through OXCNF-Cu-Tpy membrane

suspended particles. The large particles were removed by settling and the fraction containing the highly suspended particles was used in the test. Figure 9 shows the particle size distribution present in wastewater fraction used; $90 \%$ of the suspended particles were $<1.5 \mu \mathrm{m}$, whereas the average particle size was $696 \mathrm{~nm}$.

Due to the high loading of the wastewater with suspended particles, significant decrease in water flux was observed compared to filtration of pure water (Fig. 8). Flux of OXCNF-Cu-Tpy membrane was higher than that OXCNF. Wastewater flux values of about $23( \pm 1.4)$ and $28( \pm 1.2) \mathrm{l} / \mathrm{h} /$ $\mathrm{m}^{2}$ was recorded for OXCNF membrane at 0.5 and $1 \mathrm{MPa}$ pressure, respectively, while flux values of $30.4( \pm 0.7)$ and $36.6( \pm 0.5) \mathrm{l} / \mathrm{h} / \mathrm{m}^{2}$ was recorded for OXCNF-Cu-Tpy membrane at 0.5 and $1 \mathrm{MPa}$ pressure, respectively. This means about 30 and $29 \%$ increase in pure water flux at 0.5 and $1 \mathrm{MPa}$, respectively, as a result of surface modification with the $\mathrm{Cu}$-Tpy groups.

\subsection{Removal Efficiency of Wastewater Microparticles}

The efficiency of OXCNF and OXCNF-Cu-Tpy membranes in removing of wastewater particles was estimated by measuring absorbance at $600 \mathrm{~nm}$ before and after filtration through the membranes. Figure 10 shows the visible spectra of wastewater before and after filtration. Removal of the suspended particles from wastewater by the different membranes was highly efficient (93 and 96\% for OXCNF and OXCNF-Cu-Tpy membranes, respectively).

\section{Conclusions}

Ultrafiltration membranes with antimicrobial properties and improved water flux were prepared from terpyridine-modified cellulose nanofibers. These membranes demonstrated efficient removal of sub-micron size particles present in wastewater produced from papermaking from recycled fibers. Chemical modification of TEMPO-oxidized CNF with $\mathrm{Cu}$-Tpy moieties through supramolecular bonding can improve water flux and rejection efficiency of membranes prepared from the modified nanofibers.

Acknowledgements The authors acknowledge funding of the current research work by Swedish Research Council (Project No. 2015-05847) and the financial support under Bio4Energy-a strategic research environment appointed by the Swedish government.

Open Access This article is distributed under the terms of the Creative Commons Attribution 4.0 International License (http://creativecommons.org/licenses/by/4.0/), which permits unrestricted use, distribution, and reproduction in any medium, provided you give appropriate credit to the original author(s) and the source, provide a link to the Creative Commons license, and indicate if changes were made.

\section{References}

1. U.S. Schubert, A. Winter, G.R. Newkome, Terpyridine-Based Materials: For Catalytic, Optoelectronic and Life Science Applications (Wiley, Hoboken, 2011), p. 522

2. Y. Gao, D. Rajwar, A.C. Grimsdale, Macromol. Rapid Commun. 35, 1727 (2014)

3. C.E. Housecroft, Dalton Trans. 43, 6594 (2014)

4. M.L. Hassan, C.M. Moorefield, H.S. Elbatal, G.R. Newkome, J. Macromol. Sci. 49, 298 (2012)

5. M.L. Hassan, C.M. Moorefield, H.S. Elbatal, G.R. Newkome, D.A. Modarelli, N.C. Romano, Mater. Sci. Eng. B 177, 350 (2012)

6. M.L. Hassan, S.M. Fadel, A.A. Ward, C.M. Moorefield, G.R. Newkome, Polym. Compos. 37, 2734 (2016)

7. E.A. Hassan, M.L. Hassan, C.N. Moorefield, G.R. Newkome, Carbohydr. Polym. 116, 2 (2015)

8. E.A. Hassan, M.L. Hassan, Ind. Crops Prod. 93, 142 (2016)

9. J.-H. Kim, M. Gu, D.H. Lee, J.-H. Kim, Y.-S. Oh, S.H. Min, B.-S. Kim, S.-Y. Lee, Nano Lett. 16, 5533 (2016)

10. B.Z. Gönder, S. Arayici, H. Barlas, Sep. Purif. Technol. 76, 292 (2011) 
11. C. Chen, S. Mao, J. Wang, J. Bao, H. Xu, W. Su, H. Dai, BioResources 10, $2376(2015)$

12. S. Varanasi, Z.-X. Low, W. Batchelor, Chem. Eng. J. 265, 138 (2015)

13. Z. Karim, S. Claudpierre, M. Grahn, K. Oksman, A.P. Mathew, J. Membr. Sci. 514, 418 (2016)

14. M.L. Hassan, R.E. Abou-Zeid, E.A. Hassan, L. Berglund, K. Oksman, Polymers 9, 335 (2017)

15. H. Voisin, L. Bergström, P. Liu, A.P. Mathew, Nanomaterials 7, 57 (2017)

16. L.E. Wise, M. Murphy, A.A. D'Addieco, Pap. Trade J. 122, 35 (1946)
17. B.L. Browning, Methods of Wood Chemistry, vol 2 (Interscience, New York, 1967), p. 498

18. D.K. Sidiras, D.P. Koullas, A.G. Vgenopoulos, E.G. Koukios, Cell. Chem. Technol. 24(3), 309-317 (1990)

19. P. Wang, C.N. Moorefield, S. Li, S.-H. Hwang, C.D. Shreiner, G.R. Newkome, Chem. Commun. 10, 1091 (2006)

20. W. Huang, W. You, L. Wang, C. Yao, Inorg. Chim. Acta 362, 2127 (2009) 